\title{
SynCardia, total artificial heart, as a bridge to transplant
}

\author{
Hulman $\mathrm{M}^{1}$, Artemiou $\mathrm{P}^{1}$, Hudec $\mathrm{V}^{1}$, Olejarova $\mathrm{I}^{2}$, Goncalvesova $\mathrm{E}^{3}$ \\ Medical Faculty of the Slovak Medical University, National Institute of Cardiovascular diseases, \\ Clinic of Cardiac Surgery, Bratislava, Slovakia. panayiotisartemiou@yahoo.com
}

\begin{abstract}
INTRODUCTION: Implantation of a total artificial heart is an alternative to durable biventricular assist device support in selected patients. We present our initial experience with the implantation of the SynCardia total artificial heart (TAH) in three patients. The first patient, was the first SynCardia (TAH) implantation in the Visegrad Four (V4) countries

METHOD: Three patients with severe refractory end stage biventricular heart failure listed for heart transplant were indicated for SynCardia TAH implantation

RESULTS: We present in details the perioperative and postoperative outcomes of these patients. The first and the third patient, after 195 and 126 days of TAH support respectively, had a successful heart transplants, the second patient died on 11th postoperative day. The cause of death was brain bleeding due to ruptured undiagnosed brain aneurysm.

CONCLUSION: SynCardia TAH is an alternative therapy in patients with end-stage biventricular heart failure waiting for heart transplantation. The SynCardia TAH with pulsatility resembles the physiologic circulation, improves the condition of the patients and increases survival compared to the biventricular assist devices. It is an intermediate step until the development of genetically modified animal hearts, engineered bioartificial hearts or hearts from induced pluripotent stem cells that would replace the failing heart in the patients with end-stage heart disease (Tab. 2, Fig. 1, Ref. 27). Text in PDF www.elis.sk.

KEY WORDS: biventricular heart failure, total artificial heart, Syncardia TAH, biventricular assist device, heart transplantation.
\end{abstract}

\section{Introduction}

End-stage heart failure is a public health problem affecting an increasing number of patients each year. A variety of options exist for its treatment, but heart transplantation remains the gold standard (1). The lack of donors leads to an increased use of ventricular assist devices (VAD) as a bridge to transplant (BTT) or as a destination therapy (2). Among patients with advance heart failure, those with biventricular failure have the worst prognosis and very few available options while waiting for transplantation (1). Implantation of a total artificial heart (TAH) is an alternative to durable biventricular VAD support in the adult as well as in the pediatric population (3-5).

The number of heart transplants in Slovakia are 15-20 per year in a population of 5.5 million people and the median time in

${ }^{1}$ Medical Faculty of the Slovak Medical University, National Institute of Cardiovascular Diseases, Clinic of Cardiac Surgery, Bratislava, Slovakia, ${ }^{2}$ Medical Faculty of the Slovak Medical University, National Institute of Cardiovascular Diseases, Department of Anesthesiology, Bratislava, Slovakia, and ${ }^{3}$ Medical Faculty of the Slovak Medical University, National Institute of Cardiovascular Diseases, Clinic of Cardiology, Department of Heart Failure Bratislava, Slovakia

Address for correspondence: P. Artemiou, MD, National Institute of Cardiovascular Diseases, Clinic of Cardiac Surgery, Pod Krasnou horkou 1, SK-831 01 Bratislava, Slovakia.

Phone: +421.917.665774, Fax: +421.259.320287 the waiting list is 13 months. Up to the end of 2017, there were 51 patients on the waiting list and $60 \%$ of them were on LVAD support and during the last few years 5 patients with biventricular failure on paracorporeal BiVAD underwent successful heart transplants. The TAH enables these patients with biventricular failure to be discharged from the hospital, while waiting for the heart transplant. Alternative strategy for these patients is the use of durable biventricular VAD support.

In our institute, the preferred strategy is the TAH support, and in this report we present our initial experience with the implantation of the SynCardia TAH, in three patients waiting for heart transplantation with critical biventricular failure. The first patient was the first SynCardia (TAH) implantation in the Visegrad Four (V4) countries.

\section{Patients and methods}

Since January 2017, 27 durable circulatory assist devices were implanted in our institution. Biventricular assist devices were required in three patients, all of who received the SynCardia TAH as a bridge to transplant. The decision to implant a TAH over LVAD was made owing to the presence of conditions most often associated with multiorgan failure, severe preoperative right ventricular dysfunction, and a high pulmonary vascular resistance in one patient. Preoperative hemodynamic parameters including right heart catheterization were recorded during evaluation for heart 
Tab. 1. Preoperative patients` characteristics.

\begin{tabular}{|c|c|c|c|}
\hline Variable & Patient 1 & Patient 2 & Patient 3 \\
\hline \multicolumn{4}{|l|}{ Demographics } \\
\hline Age & 47 & 60 & 62 \\
\hline Sex & male & male & male \\
\hline $\mathrm{BSA}\left(\mathrm{m}^{2}\right)$ & 1.94 & 2.33 & 2.14 \\
\hline $\mathrm{BMI}\left(\mathrm{kg} / \mathrm{m}^{2}\right)$ & 25.18 & 29.09 & 27.32 \\
\hline Etiology & No-virus negative myocarditis & Dilated cardiomyopathy & Ischemic cardiomyopathy \\
\hline Prior cardiac surgery & no & no & yes, CABG 22 years ago \\
\hline \multicolumn{4}{|l|}{ Preoperative hemodynamics } \\
\hline Systolic arterial pressure $(\mathrm{mmHg})$ & 96 & 93 & 91 \\
\hline $\mathrm{MBP}(\mathrm{mmHg})$ & 87 & 77 & 75 \\
\hline central venous pressure $(\mathrm{mmHg})$ & 24 & 19 & 15 \\
\hline Systolic PAP (mmHg) & 34 & 46 & 64 \\
\hline PCWP (mmHg) & 31 & 29 & 27 \\
\hline PVR (Wood units) & 1.5 & 3 & 5.3 \\
\hline TPG (mmHg) & 4 & 10 & 18 \\
\hline $\mathrm{CI}\left(1 / \mathrm{m}^{2} / \mathrm{min}\right)$ & 1.13 & 1.5 & 1.6 \\
\hline LVEF (\%) & 10 & 20 & 20 \\
\hline NYHA class & IV & IV & IV \\
\hline INTERMACS status & 1 & 2 & 2 \\
\hline RVFAC (\%) & 25 & 18 & 25 \\
\hline TAPSE $(\mathrm{mm})$ & 10 & 10 & 8 \\
\hline \multicolumn{4}{|l|}{ Preoperative laboratory data } \\
\hline Sodium $(\mathrm{mmol} / \mathrm{l})$ & 130 & 139 & 144 \\
\hline Creatinine $(\mu \mathrm{mol} / \mathrm{l})$ & 112 & 116 & 108 \\
\hline Urea $(\mathrm{mmol} / \mathrm{l})$ & 8.9 & 13.3 & 12.9 \\
\hline total bilirubin $(\mu \mathrm{mol} / \mathrm{l})$ & 37 & 43.1 & 27.4 \\
\hline AST $(\mu \mathrm{Kat} / \mathrm{l})$ & 0.86 & 0.34 & 0.55 \\
\hline ALT $(\mu \mathrm{Kat} / \mathrm{l})$ & 0.97 & 0.38 & 0.45 \\
\hline Hemoglobin $(\mathrm{g} / \mathrm{l})$ & 150 & 138 & 155 \\
\hline NTpro BNP (ng/l) & 13301 & 7639 & 2454 \\
\hline \multicolumn{4}{|l|}{ Preoperative circulatory support } \\
\hline ECMO & yes & no & no \\
\hline Duration of ECMO support (days) & 4 & $/ 1$ & 0 \\
\hline
\end{tabular}

$\overline{\mathrm{BSA}}=$ body surface area, $\mathrm{BMI}=$ body mass index, $\mathrm{MBP}=$ mean blood pressure, $\mathrm{CABG}=$ coronary artery bypass grafting, $\mathrm{PAP}=$ pulmonary artery pressure, $\mathrm{PCWP}=$ pulmonary artery capillary wedge pressure PVR $=$ pulmonary vascular resistance, $\mathrm{TPG}=$ transpulmonary gradient, $\mathrm{LVEF}=$ left ventricular ejection fraction, $\mathrm{NYHA}=\mathrm{New}$ York heart association, INTERMACS = Interagency Registry for Mechanically Assisted Circulatory Support, RVFAC $=$ right ventricle functional area change, TAPSE $=$ tricuspid annular plane systolic excursion, AST = aspartate aminotransferase, ALT = alanine aminotransferase, NTproBNP $=\mathrm{N}$-terminal pro brain natriuretic peptide, ECMO $=$ extracorporeal membrane oxygenation

transplant eligibility. Before BiVAD implantation, we emphasize on right ventricular assessment. BiVAD is indicated when the majority of the following echocardiographic parameters are present: functional area change (FAC) $<20 \%$, tricuspid annular plane systolic excursion (TAPSE) $<8 \mathrm{~mm}, \mathrm{~S} / \mathrm{L}$ axis $<0.6, \mathrm{R} / \mathrm{L}$ in $4 \mathrm{D}$ $<0.72$, right ventricular absolute peak longitudinal strain $<9.6 \%$ and severe tricuspid regurgitation. Patients with a functional New York Heart Association (NYHA) class IV and body surface area (BSA) equal to or greater than $1.7 \mathrm{~m}^{2}$ or with an antero-posterior diameter greater than $10 \mathrm{~cm}$ (measured at T10 from the sternum to the anterior border of the vertebral body on chest computed tomography (CT) were eligible for TAH implantation.

The patients' demographics and clinical characteristics and causes of heart failure are shown in Table 1.

SynCardia TAH is a pneumatically driven TAH that replaces the failing native ventricles. The prosthetic ventricles are made of polyurethane and are attached to the left and right atria. Four monodisk mechanical prostheses (Medronic-Hall, Medronic Inc) provide an unidirectional blood flow. Each ventricle has a volume of $70 \mathrm{ml}$ and comprises a silicone diaphragm separating blood from the pneumatic chamber. The pulsed injection of compressed air allows the movement of the diaphragm and thus filling and evacuating both ventricles, which are connected to an external console via 2 drivelines (Fig. 1). The advent of mobile (Companion II) and portable (Excor TAH-t and Freedom) drivers allowed out of hospital care of SynCardia TAH recipients (6).

The surgical implantation technique has been described previously $(7,8)$. Briefly, the native ventricles were excised at the level of the atrioventricular valves, the atrial connectors were placed in the right and left atrial cuffs, the anastomosis of both great arteries was performed and the ventricles of the artificial heart were implanted. The Dacron aortic and pulmonary grafts are sealed 

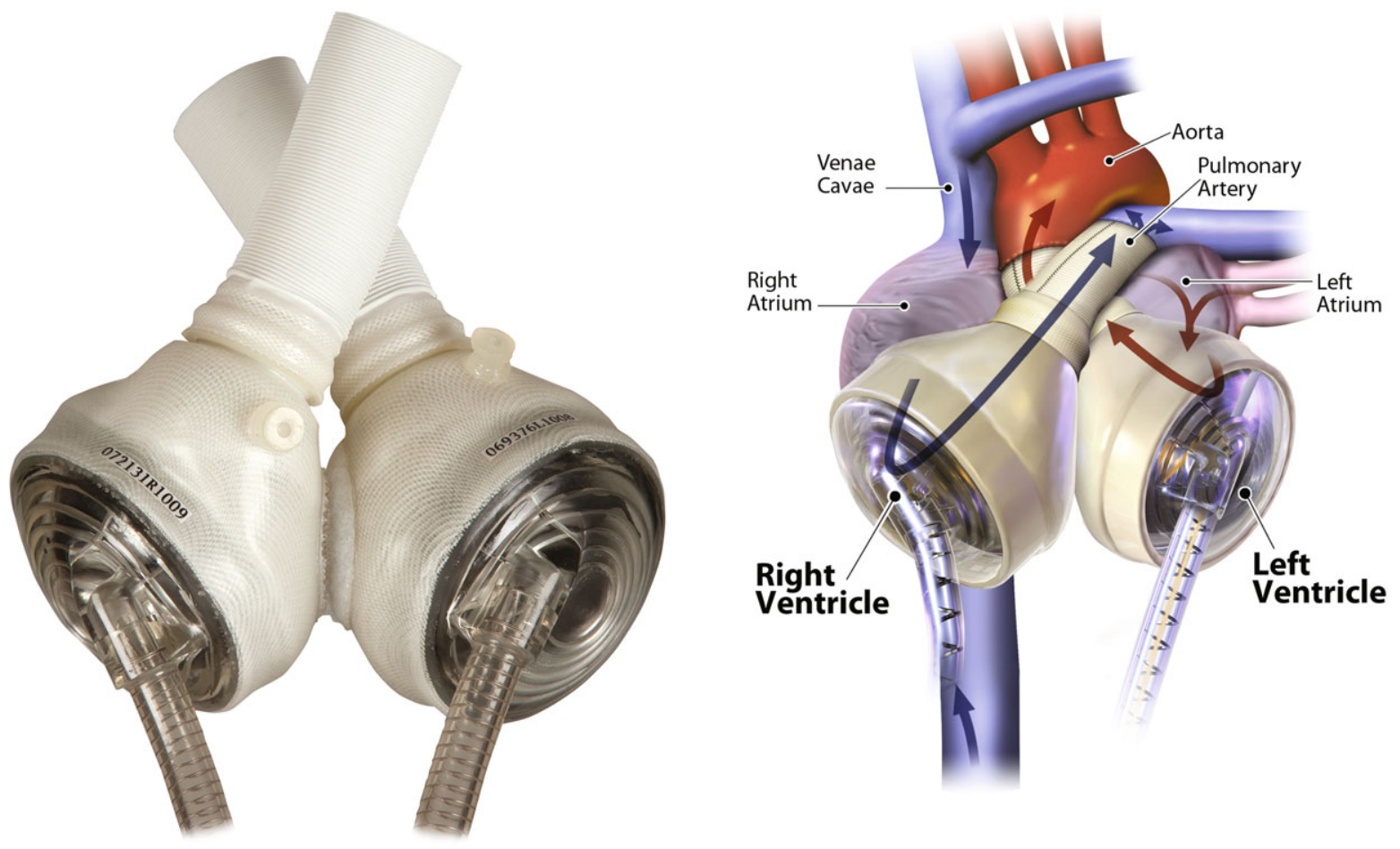

Fig. 1. Image and illustration of the SynCardia total artificial heart (Courtesy of syncardia.com).

with Coseal (Baxter Healthcare SA, Zurich, Switzerland) surgical sealant.

Postoperatively, the patients were anticoagulated systematically with acetylsalicylic acid $100 \mathrm{mg}$ daily and warfarin with target INR 2-3.5.

Clinical and laboratory data were collected from our transplantation and heart failure database. We obtained an informed consent from each patient and approval from the institutional review board in order to present these patients.

\section{Results}

\section{Patients' status before implantation}

One patient was presented with an acute heart decompensation with a critical end stage biventricular failure. For circulatory stabilization, a peripheral veno-arterial extracorporeal membrane oxygenator (VA-ECMO) was implanted with left ventricular apical venting. Four days later, the VA-ECMO was explanted and the SynCardia TAH was implanted as a BTT strategy. All of the three patients had chronic hepatic and renal failure with elevated levels of aspartate and alkaline aminotransferases, total bilirubin and creatinine. Patients were on INTERMACS status 1 or 2 and NYHA class IV.

\section{Operative characteristics}

Duration of the aortic clamp and cardiopulmonary bypass for the three patients were 105 and 130, 106 min and 117 and 124,
155 min respectively. For further heart transplant, the pericardium was fully reconstructed with a polytetrafluoroethylene membrane (PTFE) in order to simplify the re-entry for transplantation. Two of the patients left the operating room with an open chest that was closed the next day as a preventing measure in case of severe postoperative bleeding that would need surgical re-exploration.

\section{Outcomes and complications while on support}

The first and the third patient were successfully transplanted, the second patient died while on support after day 7. On the postoperative day 67 and 31 (POD), the first and the third patient with stable clinical condition and normal device function were discharged with the Freedom driver. The cause of death of the second patient was brain bleeding due to ruptured undiagnosed brain aneurysm that was found later in the postmortem examination.

Postoperative complications are listed in Table 2. Two patients suffered either ischemic stroke presented as an expressive aphasia or hemorrhagic stroke. Also, one patient had an acute renal failure that required dialysis and two patients had systemic infections. No patient experienced severe postoperative bleeding or gastrointestinal complications, as well as no device failure was observed. One patient later in the follow-up had a sternal wound infection. The length of stay in the intensive care unit was 14,7 and 11 days respectively. All the three patients between POD 2 and 4 were weaned from mechanical ventilator support.

In one patient during the time of Freedom driver, one malfunction of the driver appeared due to mechanical damage of the 
Tab. 2. Outcomes of total artificial heart support.

\begin{tabular}{|c|c|c|c|}
\hline Variable & Patient 1 & Patient 2 & Patient 3 \\
\hline Duration of support (days) & 195 & 7 & 126 \\
\hline \multicolumn{4}{|l|}{ Outcome } \\
\hline Ongoing & no & no & no \\
\hline Died on support & no & yes & no \\
\hline Transplanted & yes & no & yes \\
\hline \multicolumn{4}{|l|}{ Neurologic events } \\
\hline $\operatorname{TIA}(<24 \mathrm{~h})$ & no & no & no \\
\hline Stroke & yes & yes & no \\
\hline Cerebral bleeding & no & yes* & no \\
\hline Ischemic stroke & yes & no & no \\
\hline $\begin{array}{l}\text { Bleeding requiring } \\
\text { reoperation }\end{array}$ & no & no & no \\
\hline Infection & yes & no & yes \\
\hline $\begin{array}{l}\text { Gastrointestinal } \\
\text { complications }\end{array}$ & no & no & no \\
\hline $\begin{array}{l}\text { Acute renal failure } \\
\text { requiring dialysis }\end{array}$ & no & yes & no \\
\hline Device failure & no & no & no \\
\hline Sternal wound infection & no & no & yes \\
\hline
\end{tabular}

system controller. Cessation of the pump function was managed successfully by controller change.

\section{Outcomes after transplantation}

Two patients were successfully bridged to transplant after 195 and 126 days of TAH support respectively. Before, they were discharged on POD 67 and 31 respectively with a portable console (Freedom driver). In the first patient, the postoperative course was complicated by a primary graft dysfunction that was treated with a temporary right ventricular assist device (RVAD) and few surgical re-explorations due to severe postoperative bleeding. On POD 42, he was discharged home and nine months after the heart transplant he is in good condition. In the second patient, the postoperative course was complicated by right ventricular dysfunction that was managed conservatively and by postoperative bleeding that required surgical re-exploration. Also, on POD 41, he was discharged in stable condition.

\section{Discussion}

In the present study, we reviewed our recent experience with patients, who underwent mechanical bridge to transplant using the SynCardia TAH. Our results showed that this device provided acceptable survival rates to transplantation. Clinical investigations showed that the INTERMACS profile had an impact on survival, where INTERMACS profile 1 had reduced survival to transplantation rates compared with the less sick profiles (9).

Patients with concurrent right ventricular failure in addition to left ventricular failure had poorer outcomes with left ventricular assist devices (LVAD) than the patients with isolated left ventricular failure (10). In these patients, biventricular support was indicated. While the TAH provides a definite biventricular support, paracorporeal biventricular VAD (BiVAD) provides an alternative strategy and this includes temporary and durable RVAD. Initial biventricular mechanical support for critically ill patients usually provides a higher cardiac output, which can help resuscitate end organ malperfusion (10). Among the various devices available to support patients with biventricular failure, the SynCardia TAH is used less frequently than paracorporeal BiVADs according to the latest INTERMACS Registry (2). Our group uses preferentially the SynCardia TAH in this indication, while other devices are employed only if myocardial recovery is expected or in the case of a contraindication to TAH. Other indications considering the use of SynCardia TAH are patients with malignant uncontrolled ventricular tachyarrhythmias, patients with complex congenital heart diseases and those with ventricular morphology unsuitable for LVAD implantation.

Moreover, our BTT preferred strategy with the use of the SynCardia TAH is based on the following reasons i) in the Slovakian health system, the use of the SynCardia TAH is a cheaper alternative than the use of durable LVAD and RVAD devices ii) the use of durable LVAD and RVAD devices requires its optimal synchronization, where on the contrary, the use of the SynCardia TAH does not need such synchronization iii) the SynCardia TAH provides a pulsatile flow, which is more physiologic in contrary to the continuous flow that is provided by the current durable LVAD and RVAD devices iv) there is no need for extra anticoagulation management since it is the same as with the current LVAD and RVAD devices v) LVAD- related complications like right heart failure, aortic valve insufficiency, mitral and tricuspid valve regurgitation and arrhythmias (atrial fibrillation, ventricular tachycardia/fibrillation) are eliminated with TAH and finally vi) in the near future, the new SynCardia TAH devices would be less noisy, which would mean an important improvement in the quality of patient's life.

While no head-to-head prospective randomized controlled trials have compared these two types of mechanical circulatory support, one small retrospective study showed no difference in mortality for patients implanted with a TAH compared with BiVAD (11). On the other hand, analysis of the latest INTERMACS registry suggested an improved survival of the patients implanted with a TAH compared to BiVADs by $9 \%$ (2).

Non-randomized studies showed that survival as BTT and after heart transplant is similar between TAH and BiVAD support (12). In our study, two patients underwent successful heart transplant after 195 and 126 days of TAH support respectively, and at the latest follow-up, both patients are in good condition.

Larger studies $(3,13,14)$ showed that SynCardia TAH is an alternative therapy with low incidence of neurologic events in extremely complex patients awaiting transplantation. Nevertheless, our observed stroke incidence in this limited series was higher than that the one observed with current generation continuous flow LVADs $(12,15)$. Furthermore, a report from the GRAM registry showed that SynCardia TAH recipients had significantly fewer neurologic events than BiVAD recipients (11). Further reduction of stroke can be expected with TAH devices using bioprosthetic 
heart valves for unidirectional blood flow (16), but with the expense of probable limited durability due to high levels of mechanical stress in assist devices that might accelerate structural changes of the bioprosthetic heart valves.

One patient had renal failure that needed postoperative replacement therapy, and two patients had systemic infection. These results are comparable to those reported around the world. (12). Comparative studies showed that the renal failure rate was significantly higher in the TAH support group than the BiVAD support group after implantation (12). On the other hand, the infection rate after implantation was significantly lower in the TAH group than the BiVAD group (12). Most commonly, infections in the TAH group were respiratory and genitourinary. Two of our patients experienced systemic infections.

In our study, no patients experienced severe bleeding events or device malfunction. Bleeding events were reported to be between $43 \%$ and $62 \%$ in the TAH group patients (12). Previous studies also showed that the surgical revision for bleeding or hematoma was significantly lower in the TAH group than the BiVAD group ( $23 \%$ vs $42 \%$ ). Of these events, $50 \%$ occurred during TAH implantation and were mainly tamponade or mediastinal bleeding within 21 days.

In our study, in accordance with other published series (17), the two patients that underwent successful heart transplant after the TAH implantation had an improvement in pulmonary artery pressures, trans-pulmonary gradient and pulmonary vascular resistance during the TAH support. It seems reasonable that patients, who received a TAH implant amid elevated pulmonary artery pressures should benefit from direct monitoring, and a novel method with the CardioMEMS Heart Failure system (St. Jude Medical, Little Canada, MN) had been successfully used (18).

Finally, device malfunction was reported to be in non-randomized studies between $10 \%$ and $25 \%$ of the patients in the TAH group (11). In our cases, only one mechanical malfunction of the Freedom driver system controller due to mechanical damage appeared in one patient, which was managed successfully by controller change. Mechanical damage of the system controller of the Freedom driver has not yet been reported. In 2015, the Federal Drug Agency issued a Class I recall of a selected number of SynCardia systems total artificial heart Freedom driver. A specific part of the Freedom driver mechanism could fail causing a driver failure without any advanced warning.

Common problems in the long-term management in both survived patients were anemia of unknown origin and a need of high doses of diuretics for edemas and adequate diuresis. Mankad et al (19), also reported that patients implanted with a TAH had laboratory evidence of hemolysis and persistent anemia that resolved only after heart transplant. Similar evidence of laboratory hemolysis had our patients as well. The association of hemolysis, ineffective erythropoesis, and inflammation with the TAH warrants further studies. In TAH implantation, resection of the native ventricles results in a rapid decrease of endogenous brain natriuretic peptides (BNP) and this may induce a decline in renal function as in our cases, where in the long-term management high doses of diuretics were needed (20).

\section{Conclusion}

Based on our limited experience, the SynCardia TAH is an alternative therapy in patients with end-stage biventricular heart failure awaiting heart transplant. Whether TAH technology advances to the point, where it becomes a viable alternative to transplantation, remains to be seen. There are several challenges to overcome. Achieving an adequate durability ( $>5$ years), minimizing thromboemboli and hemolysis, better efficiency, maintaining pulmonary-systemic circulatory balance and, reduced size to accommodate in women and small adolescents and children are examples (20). Greater autonomous balance between pulmonary and systemic flow intrinsic to rotary pumps might lead to rotary TAHs succeeding there, where the previous attempts have failed (22-26). Finally, the future step is the development of bioartificial engineered hearts, however a number of technological barriers remain before a bioartificial heart can move towards preclinical testing and eventually to clinical application (27).

\section{Learning points}

The SynCardia total artificial heart as a bridge to transplant is a viable alternative method in the patients with severe biventricular heart failure

\section{References}

1. Cleveland JC, Naftel DC, Reece TB et al. Survival after biventricular assist device implantation: an analysis of the interagency registry for mechanically assisted circulatory support database. J Heart Lung Transplant 2011; 30: 862-869.

2. Arabia FA, Cantor RS, Koehl DA et al. Interagency registry for mechanically assisted circulatory support report on the total artificial heart. J Heart Lung Transplant 2018; 37: 1298-1300.

3. Copeland JG, Copeland H, Gustafson M et al. Experience with more than 100 total artificial heart implants. J Thorac Cardiovasc Surg 2012; 143: 727-734.

4. Rangwala Z, Banks DA, Copeland JG. Pro: The total artificial heart: Is it an appropriate replacement for existing biventricular assist devices? J Cardiothorac Vasc Anesth 2014; 28 (3): 836-839.

5. Morales DLS, Lorts A, Rizwan R et al. Worldwide experience with the Syncardia total artificial heart in the pediatric population. ASAIO J 2017; 63: 518-519.

6. Copeland J. Out of hospital total artificial heart patients. Texas Heart Inst J 2010; 37: 654-655.

7. Torregosa G, Anyanwu A, Zucchetta F, Gerosa G. SynCardia: the total artificial heart. Ann Cardiothorac Surg 2014; 3 (6): 612-620.

8. Karimov JH, Gao S, Dessoffy R et al. Novel technique for airless connection of artificial heart to vascular conduits. J Artif Organs 2017; 20: 386-389.

9. Shah KB, Thanavaro KL, Tang DG et al. Impact of INTERMACS profile on clinical outcomes for patients supported with the total artificial heart. J Card Fail 2016; 22 (11): 913-919.

10. Cook JA, Shah KB, Quader MA et al. The total artificial heart. J Thorac Dis 2015; 7 (12): 2172-2180. 


\section{$325-330$}

11. Kirsch M, Mazzucotelli JP, Roussel JC et al. Survival after biventricular mechanical circulatory support: does the type of device matter? J Heart Lung Transplant 2012; 31: 501-518.

12. National Institute for Health and Care Excellence. Artificial heart implantation as a bridge to transplantation for end-stage refractory biventricular heart failure. https: //nice.org.uk/guidance/ipg602 (accessed 20 December 2017)

13. Nguyen A, Pellerin A, Perrault LP et al. Experience with Syncardia total artificial heart in a Canadian centre. Can J Surg 2017; 60 (6): 375-379.

14. Kirsch MEW, Nguyen A, Mastroianni C et al. Syncardia temporary total artificial heart as bridge to transplantion: Current results at La Pitie Hospital. Ann Thorac Surg 2013; 95: 1640-1646.

15. Backes D, van den Bergh W, van Duijn AL, Lahpor JR, van Dijk D, Slooter AJC. Cerebrovascular complications of left ventricular assist devices. Eur J Cardiothorac Surg 2012; 42: 612-620.

16. Latremouille C, Carpentier A, Leprince $P$ et al. A bioprosthetic total artificial heart for end-stage heart failure: Results from a pilot study. J Heart Lung Transpl 2018; 37: 33-37.

17. Joyce DL, Redfield MM, Kushwaha SS et al. Pulmonary pressure assessment with the total artificial heart. ASAIO J 2018; 64: e34-e36.

18. Gohar S, Taimeh ZA, Morgan AJ et al. Use of remote pulmonary artery pressure monitoring (CardioMEMS System) in total artificial heart to assess pulmonary hemodynamics for heart transplantation. ASAIO J 2018; 64: e75-e77.

19. Mankad AK, Tang DG, Clark WB et al. Persistent anemia after implantation of the total artificial heart. J Cardiac Fail 2012; 18: 433-438.
20. Spiliopouls S, Guersoy D, Koerfer R, Tenderich G. B-type natriuretic peptide therapy in total artificial heart implantation: Renal effects with early initiation. J Heart Lung Transplant 2014; 33: 6: 662-663.

21. Fox C, Chopski S, Murat $\mathbf{N}$ et al. Hybrid continuous-flow total artificial heart. J Artif Organs 2018; 42 (5): 500-509.

22. Goerlich CE, Frazier OH, Cohn WE. Previous challenges and current progress-the use of total artificial hearts in patients with end-stage heart failure. Expert Rev Cardiovasc Ther 2016; 10 (14): 1095-1098.

23. Fukamachi K, Karimov JH, Sunagawa G et al. Generating pulsatility by pump speed modulation with continuous-flow total artificial heart in awake calves. J Artif Organs 2017; 20: 381-385.

24. Fukamachi K, Karimov JH, Byram NA et al. Anatomical study of the Cleveland clinic continuous-flow total artificial heart in adult and pediatric configuration. J Artif Organs 2018; 21: 383-386.

25. Fukamachi K, Karimov JH, Horvath DJ et al. Initial in vitro testing of a paediatric continuous-flow total artificial heart. Interact Cardiovasc Thorac Surg 2018; 26: 897-901.

26. Unthan K, Cuenca-Navalon E, Pelletier B, Finocchiaro T, Steinseifer U. Driver electronics design and control for a total artificial heart linear monitor. Med Biol Eng Comp 2018; 56: 1487-1498.

27. Taylor DA, Frazier OH, Elgalad A, Hochman-Mendez C, Sampaio LC. Building a total bioartificial heart: Harnessing nature to overcome the current hurdles. Artif Organs 2018; 42 (10): 970-982.

Received February 13, 2019. Accepted March 7, 2019. 